\title{
Prophylactic intra-aortic balloon pump in patients with left main disease undergoing off-pump coronary artery bypass grafting
}

\author{
Ju-Bing Zheng, Kun Hua, Kui Zhang, Shao-You Zhou, Shi-Jun Xu, Juan-Juan Sheng and Ran Dong* ${ }^{*}$
}

\begin{abstract}
Background: Preventive intra-aortic balloon pump (IABP) for high-risk patients with stable hemodynamics is controversial, and its definition of high-risk is still unclear. This study aimed to investigate the effect of prophylactic IABP on the early outcome of left main disease (LMD) patients receiving off-pump coronary artery bypass grafting (OPCABG) with stable hemodynamics.
\end{abstract}

Methods: From January 2013 to April 2020, 257 consecutive patients who underwent OPCABG through sternotomy were enrolled in this study. All LMD patients (greater than 70\%) had stable hemodynamics (BP>100 mmHg without vasoconstrictor substance infusion). Early outcomes of 125 patients with prophylactic IABP (IABP group) and 132 patients without IABP (Control group) were compared in this study.

Results: IABP did not show favorable effect on the conversion to CPB (RR 0.63, 95\%Cl 0.05-7.89, $P=0.7211$ ), perioperative MI (RR 0.69,95\%Cl 0.22-2.12, $P=0.5163$ ), mortality (RR $0.65,95 \% \mathrm{Cl} 0.04-10.25, P=0.7608$ ) or the composite end of the conversion, $\mathrm{Ml}$ and mortality (RR $0.63,95 \% \mathrm{Cl} 0.23-1.74, P=0.3747$ ). There was greater incidence of prolonged ventilation in IABP after adjustment (RR2.16, 95\% Cl 1.12-4.18, $P=0.0221$ ). There was no IABP-related mortality or limb ischemia.

Conclusion: No significant difference in early outcomes was observed in hemodynamically stable patients with LMD between prophylactic IABP group and control group. Prophylactic IABP may be unnecessary in patients with LMD undergoing OPCABG.

Keywords: Left Main disease, Off-pump coronary artery bypass grafting, Intra-aortic balloon pump

\section{Background}

Intra-aortic Balloon Pump (IABP) is the most commonly used circulatory assist device in the treatment of intractable angina, cardiogenic shock or heart failure, and complications of myocardial infarction. It could provide more favorable myocardial blood supply by increasing diastolic pressure $[1,2]$. In recent years, preoperative prophylactic IABP for high-risk patients with stable hemodynamics has been reported and there is controversy about this [3-7].

\footnotetext{
* Correspondence: dongran6618@126.com

Department of Cardiac Surgery, Beijing Anzhen Hospital, Capital Medical University, No. 2 Anzhen Street, Chaoyang District, Beijing 100029, China
}

In addition, the definition of high risks is unclear because it is usually a combination of at least 2 of the following risk factors: poor ejection fraction (EF), advanced age, presence of mitral regurgitation, left main coronary artery disease, redo coronary artery bypass grafting (CABG), New York Heart Association (NYHA) class III or IV, urgent or emergent $\mathrm{CABG}$, and left ventricular end diastolic pressure $>20 \mathrm{mmHg}$ etc. $[8,9]$. However, report of prophylactic IABP in patients with left main artery disease (LMD) who underwent off-pump coronary artery bypass grafting (OPCABG) remains limited. In addition, neither off-pump coronary artery bypass grafting (OPCAB) or on-

C C The Author(s). 2020 Open Access This article is licensed under a Creative Commons Attribution 4.0 International License, which permits use, sharing, adaptation, distribution and reproduction in any medium or format, as long as you give appropriate credit to the original author(s) and the source, provide a link to the Creative Commons licence, and indicate if changes were made. The images or other third party material in this article are included in the article's Creative Commons licence, unless indicated otherwise in a credit line to the material. If material is not included in the article's Creative Commons licence and your intended use is not permitted by statutory regulation or exceeds the permitted use, you will need to obtain permission directly from the copyright holder. To view a copy of this licence, visit http://creativecommons.org/licenses/by/4.0/ The Creative Commons Public Domain Dedication waiver (http://creativecommons.org/publicdomain/zero/1.0/) applies to the data made available in this article, unless otherwise stated in a credit line to the data. 
pump CABG in these studies has evaluated the stratification of IABP. The role of preventive IABP in isolated LMD patients receiving OPCAB is unclear. The purpose of this study was to investigate the effect of prophylactic IABP on the early outcome of LMD patients receiving OPCABG with stable hemodynamics.

\section{Methods}

\section{Patients}

From January 2013 to April 2020, 257 consecutive patients who underwent OPCABG through sternotomy were enrolled in this study. All LMD patients (greater than $70 \%$ ) had stable hemodynamics (BP>100 $\mathrm{mmHg}$ without vasoconstrictor substance infusion).

Exclusion criteria: patients undergoing emergency or urgent operations due to unstable hemodynamics or intractable angina; patients with mechanical complications due to acute myocardial infarction; patients with poorly preoperative ventricular arrhythmias control; patients with myocardial infarction within 3 days; patients with unstable angina due to persistent myocardial infarction. Early outcomes of 125 patients with prophylactic IABP (IABP group) and 132 patients without IABP (Control group) were compared in this study. The longest followup time was 1 year. This study was approved by the Beijing Anzhen Hospital Ethic Committee. Informed consent was obtained from all individual participants included in the study.

\section{IABP insertion and timing}

One hundred twenty five patients received prophylactic IABP support according to the decision of surgeons. Intraaortic balloon was percutaneous inserted into the common femoral artery $30 \mathrm{~min}$ before the operation. After IABP insertion, all patients were anticoagulated with heparin to maintain the activated partial thromboplastin time 1.5-2 times the normal value. In all patients receiving IABP insertion, 9.5F Percor balloon was percutaneous inserted into the common femoral artery using 10F sheath.

\section{Surgical procedure}

All procedures were performed through a median sternotomy. After left internal mammary artery (LIMA) and saphenous vein (SV) were harvested, heparin was injected into the patient to keep an activated clotting time above $250 \mathrm{~s}$. Suction-type mechanical stabilizer (Octopus, TS2000) was used to immobilize the target coronary artery. The distal anastomosis was completed with $7-0$ or $8-0$ polypropylene and standard techniques. LIMA was separately grafted to left anterior descending (LAD). SV was sequentially grafted to obtuse marginal $(\mathrm{OM})$, diagonal and posterior descending artery (PDA) if needed. In some cases, SV was grafted to LAD because of poor flow of LIMA.

\section{Statistical analysis}

Continuous variables are provided as median (quartile) or mean \pm standard deviation (SD) based on the data dispersion. Classification variables are expressed as percentages. T-test is used to compare whether continuous variables obey normal distribution. If the variables are skew distribution, then non parametric Mann Whitney $\mathrm{U}$ test is used. Chi square test was used to compare the classified variables. Logistic regression analysis was used to determine the effect of IABP on postoperative outcome. Both unadjusted and multivariable adjusted models are applicable. All analyses were performed using statistical package R (http://www.r-project.org, R Foundation) and empower stats (http://www.empower stats. com, X \&amp; Y solutions, Inc., Boston, MA). A bilateral significance level of 0.05 was considered statistically significant.

\section{Result}

The Table 1 showed the baseline characteristic of the patients. Univariate analysis showed that patients receiving IABP were more likely to have diabetes, myocardial infarction (MI), lower ejection fraction (EF), left ventricular diastolic dimension (LVDD), higher New York Heart Association class (NYHA), left internal mammary artery (LIMA) (Table 1).

Table 2 showed the crude outcomes of the patients undergoing $\mathrm{OPCAB}$. The 30-day mortality rate was $1.52 \%$ in the control group and $1.6 \%$ in the prophylactic IABP group $(P>0.05)$. The percent of conversion to $\mathrm{CPB}$ was $3.79 \%$ in the control group and $2.4 \%$ in the IABP group $(P>0.05)$. The incidence of perioperative MI was $9.85 \%$ in the control group and $5.6 \%$ in the IABP group $(P>0.05)$. The composite of the conversion to $\mathrm{CPB}, \mathrm{MI}$ and mortality was $13.6 \%$ in the control group and $8.8 \%$ in the prophylactic IABP group $(P>0.05)$. There was greater incidence of prolonged ventilation ( $47.2 \%$ vs. $22.7 \%, P<0.001)$ and longer hospital stay $(11.25 \pm 4.41$ vs. $9.77 \pm 3.84, P=0.005)$ in IABP group.

Table 3 demonstrated the adjusted outcomes after logistic regression analysis. IABP did not show favorable effect on the conversion to CPB (RR 0.63, 95\% CI 0.05-7.89, $P=$ 0.7211 ), perioperative MI (RR $0.69,95 \% \mathrm{CI} 0.22-2.12, P=$ 0.5163 ), mortality (RR $0.65,95 \%$ CI $0.04-10.25, P=0.7608$ ) or the composite end of the conversion, MI and mortality (RR 0.63, 95\%CI 0.23-1.74, $P=0.3747$ ). There was greater incidence of prolonged ventilation in IABP after adjustment (RR2.16, 95\%CI 1.12-4.18, $P=0.0221$ ).

There was no IABP-related mortality or limb ischemia.

\section{Discussion}

The main finding of this study is that there is no significant difference in early prognosis between the IABP group and the control group. There was no significant 
Table 1 Baseline characteristic of patient population

\begin{tabular}{|c|c|c|c|}
\hline & $\begin{array}{l}\text { Control group } \\
(N=132)\end{array}$ & $\begin{array}{l}\text { IABP group } \\
(N=125)\end{array}$ & $P$ value \\
\hline Age(y) & $62.4 \pm 8.4$ & $62.6 \pm 8.5$ & 0.81 \\
\hline Male (\%) & $113(85.6 \%)$ & 96 (76.8\%) & 0.07 \\
\hline BMl & $25.3 \pm 3.8$ & $25.3 \pm 2.9$ & 0.86 \\
\hline Smoker (\%) & $72(54.5 \%)$ & $65(52.0 \%)$ & 0.68 \\
\hline Hypertention (\%) & $73(55.3 \%)$ & $69(55.2 \%)$ & 0.98 \\
\hline Diabetes (\%) & 35 (26.5\%) & 47 (37.9\%) & 0.05 \\
\hline MI (\%) & $12(9.1 \%)$ & $35(28.0 \%)$ & $<0.001$ \\
\hline COPD (\%) & $2(1.5 \%)$ & $5(4.0 \%)$ & 0.22 \\
\hline PCl (\%) & $8(9.6 \%)$ & $12(6.1 \%)$ & 0.30 \\
\hline Cholesterol (mmol/l) & $5.2 \pm 9.3$ & $4.1 \pm 1.7$ & 0.14 \\
\hline Creatinine (umol/l) & $75.0 \pm 19.0$ & $79.9 \pm 23.1$ & 0.07 \\
\hline$E F(\%)$ & $61.9 \pm 7.4$ & $52.5 \pm 11.3$ & $<0.001$ \\
\hline LVDD (mm) & $51.2 \pm 6.8$ & $47.8 \pm 4.4$ & $<0.001$ \\
\hline NYHA class & & & $<0.001$ \\
\hline$\|$ & $112(87.5 \%)$ & 77 (62.6\%) & \\
\hline III & $15(11.7 \%)$ & $46(37.4 \%)$ & \\
\hline IV & $1(0.78 \%)$ & $0(0 \%)$ & \\
\hline Unstable angina & $97(73.5 \%)$ & $91(72.8 \%)$ & 0.90 \\
\hline Carotid artery stenosis, n (\%) & $28(21.5 \%)$ & $16(12.9 \%)$ & 0.07 \\
\hline Stoke & $1(0.8 \%)$ & $2(1.6 \%)$ & 0.53 \\
\hline Grafts, n & & & 0.630 \\
\hline 2 & 15 (11.4\%) & $16(12.8 \%)$ & \\
\hline 3 & 96 (73.2\%) & 85 (68.0\%) & \\
\hline 4 & 20 (15.2\%) & $24(19.2 \%)$ & \\
\hline LIMA & 86 (65.6\%) & 65 (52.0\%) & 0.026 \\
\hline
\end{tabular}

$M I$ Myocardial infarction, COPD Obstructive pulmonary disease, $\mathrm{PCl}$ Percutaneous coronary intervention, EF Ejection faction, $L V D D$ Left ventricula diastolic dimension, NYHA New York Heart Association, LIMA Left internal mammary artery

Table 2 The crude outcomes of the patients

\begin{tabular}{llll}
\hline & $\begin{array}{l}\text { Control group } \\
(\mathrm{N}=132)\end{array}$ & $\begin{array}{l}\text { IABP group } \\
(\mathrm{N}=125)\end{array}$ & $P$-value \\
\hline Conversion to CPB & $5(3.79 \%)$ & $3(2.40 \%)$ & 0.522 \\
Perioperative MI & $13(9.85 \%)$ & $7(5.60 \%)$ & 0.204 \\
Mortality & $2(1.52 \%)$ & $2(1.60 \%)$ & 0.956 \\
Composite end & $18(13.6 \%)$ & $11(8.8 \%)$ & 0.221 \\
Bleeding for reexploring & $4(3.03 \%)$ & $3(2.40 \%)$ & 0.756 \\
Dialysis & $1(0.76 \%)$ & $3(2.40 \%)$ & 0.288 \\
Ventilation time > 24h & $30(22.7 \%)$ & $59(47.2 \%)$ & $<0.001$ \\
Hospital stay & $9.77 \pm 3.84$ & $11.25 \pm 4.41$ & 0.005 \\
\hline
\end{tabular}

CPB Cardiopulmonary bypass, MI Myocardial infarction, Composite end $=$ Conversion to $\mathrm{CPB}+\mathrm{Ml}+$ Mortality
Table $\mathbf{3}$ The Adjusted outcomes of the patients

\begin{tabular}{|c|c|c|c|c|}
\hline \multirow[t]{2}{*}{$I A B P$} & \multicolumn{2}{|l|}{ Unadjusted } & \multicolumn{2}{|l|}{ Adjusted } \\
\hline & RR $(95 \% \mathrm{Cl})$ & $P$ & $\mathrm{RR}(95 \% \mathrm{Cl})$ & $P$ \\
\hline Conversion to CPB & $0.62(0.15,2.67)$ & 0.5254 & $0.63(0.05,7.89)$ & 0.7211 \\
\hline Perioperative Ml & $0.54(0.21,1.41)$ & 0.2094 & $0.69(0.22,2.12)$ & 0.5163 \\
\hline Mortality & $1.06(0.15,7.62)$ & 0.9562 & $0.65(0.04,10.25)$ & 0.7608 \\
\hline Composite end & $0.61(0.28,1.35)$ & 0.224 & $0.63(0.23,1.74)$ & 0.3747 \\
\hline $\begin{array}{l}\text { Bleeding for } \\
\text { reexploring }\end{array}$ & $0.79(0.17,3.59)$ & 0.7569 & $0.94(0.14,6.21)$ & 0.9503 \\
\hline Dialysis & $3.22(0.33,31.38)$ & 0.3139 & $0.65(0.02,25.87)$ & 0.8173 \\
\hline $\begin{array}{l}\text { Ventilation } \\
\text { time }>24 \mathrm{~h}\end{array}$ & $3.04(1.78,5.20))$ & $<0.001$ & $2.16(1.12,4.18)$ & 0.0221 \\
\hline
\end{tabular}

difference between the two groups in terms of mortality and comprehensive indicators of myocardial infarction. In LMD patients receiving OPCAB, preventive IABP may not be necessary.

Left main coronary artery stenosis $>70 \%$ is one of the risk factors for operative death in patients undergoing CABG, although there is controversy in identifying highrisk patients [9]. Calcified ascending aorta and aortic root are more likely to occur in patients with LMD, which may lead to severe ischemia, and intractable ventricular fibrillation in case of displacement of heart during OPCABG [10]. The most severe complication of OPCABG is hemodynamic compromise or collapse, which usually leads to conversion to $\mathrm{CPB}$ [11].

Preventive IABP after high risk CABG is controversial. Christenson et al. [12] randomized 138 patients with a combination of at least 2 of the following risk factors: $\mathrm{LVEF}<40 \%$, unstable angina, redo, left main coronary stenosis $\geq 70 \%$ to receive IABP preoperatively versus no preoperative IABP. Hospital mortality was $1.4 \%$ in treatment group and $15.9 \%$ in the control group, and there was significant difference. Other studies [13-17] also showed the effectiveness of prophylactic IABP in patients with high risks. IABP scores were established to identify patients at risk for low cardiac output syndrome who may benefit from selective implantation of IABP during CABG [18].

Other studies did not demonstrate the favorable outcomes in IABP groups. Holman et al. [7] compared 550 patients treated with preventive precut balloon pump with 550 patients not treated with preventive precut balloon pump. There was no significant difference in survival rate between patients treated with preventive precut balloon pump and those not treated with preventive precut balloon pump. However, compared with patients who did not receive balloon pump, survival patients who received balloon pump before incision had significantly shorter postoperative residence time 
$(7+7.3$ days $) \quad(8+6.2$ days; $P<0.05)$. Emmert et al. [18] also reported that routine off-pump coronary artery bypass grafting is safe and feasible in high-risk patient with left main disease. In our treatment of OPCABG for patients with isolated LMD, LAD was usually grafted with LIMA before cardiac movement and examination of OM and PDA to avoid severe ischemia or hemodynamic collapse due to cardiac displacement. Since no significant difference in early outcomes were observed between IABP group and control group, LMD may be less dangerous than other high risks such as heart failure or low EF during OPCAB. Prophylactic IABP may be unnecessary in patients with LMD undergoing OPCAB.

It is reported that the postoperative stay time of patients receiving IABP is significantly shorter [7]. But in our study, the preventive IABP group had longer hospitalization time and a greater incidence of prolonged ventilation. The reason is not clear. We supposed that the degree of stenosis of left main artery in IABP group is larger, which may lead to more serious myocardial ischemia and need longer support or recovery. In our study, there was no IABP-related mortality or limb ischemia. Cohen et al. [19] reported the percentage of IABP-related mortality was $0.053 \%$, major limb ischemia was $0.9 \%$ and severe bleeding was $0.9 \%$. In our study, preoperative ultrasound examination on femoral artery and cautious insertion may help to reduce the incidence of IABP-related morbidity.

There are some limitations to our study. First, the small sample size and the nature of retrospective design weakens the strength of the paper. Second, only early outcomes were analyzed in our study. Third, single center experience needs to be testified in other units. More randomized clinical trials on this topic should be designed to evaluate the role of prophylactic IABP in LMD or other high risk patients in future.

\section{Conclusion}

No significant difference in early outcomes was observed in hemodynamically stable patients with LMD between prophylactic IABP group and control group. Prophylactic IABP may be unnecessary in patients with LMD undergoing OPCABG.

\section{Abbreviations}

IABP: Intra-aortic balloon pump; LMD: Left main disease; OPCABG: Off-pump coronary artery bypass grafting; BP: Blood pressure; RR: Relative risk; $\mathrm{Cl}$ : Confidence interval; MI: Myocardial infarction; EF: Ejection fraction; CABG: Coronary artery bypass grafting; NYHA: New York heart association; LIMA: Left internal mammary artery; SV: Saphenous vein; LAD: Left anterior descending; OM: Obtuse marginal; PDA: Posterior descending artery; standard deviation (SD); LVDD: Left ventricular diastolic dimension; COPD: Obstructive pulmonary disease; PCl: Percutaneous coronary intervention; EF: Ejection faction; CPB: Cardiopulmonary bypass; Composite end: Conversion to $\mathrm{CPB}+\mathrm{Ml}+$ Mortality
}

Acknowledgments

None to declare.

Authors' contributions

Study design: JZ, RD; Data collection and analysis: KH, KZ, SZ; interpretation of data: SX, JS; Article drafting: JZ, RD. SX and JS contributed to the revised version, all authors approved they can be included as authors. The authors have read and approved the final manuscript.

Funding

There was no funding for this study.

Availability of data and materials

The data used to support the findings of this study are available from the corresponding author upon reasonable request.

Ethics approval and consent to participate

This study was approved by the Ethics Committee of the Beijing Anzhen Hospital, Capital Medical University. All participants signed informed consent forms.

Consent for publication

Not applicable.

\section{Competing interests}

The authors declare that they have no conflict of interest.

Received: 6 February 2020 Accepted: 26 May 2020

Published online: 03 June 2020

\section{References}

1. Davidson J, Baumgariner F, Omari B, Milliken J. Intra-aortic balloon pump: indications and complications. J Natl Med Assoc. 1998;90:137-40.

2. van Nunen LX, Noc M, Kapur NK, Patel MR, Perera D, Pijls NH. Usefulness of intra-aortic balloon pump Counterpulsation. Am J Cardiol. 2016;117:469-76.

3. Ihdayhid AR, Chopra S, Rankin J. Intra-aortic balloon pump: indications, efficacy, guidelines and future directions. Curr Opin Cardiol. 2014;29:285-92.

4. Ding W, Ji Q, Wei Q, Shi Y, Ma R, Wang C. Prophylactic application of an intra-aortic balloon pump in high-risk patients undergoing off-pump coronary artery bypass grafting. Cardiology. 2015;131:109-15.

5. Sa MP, Ferraz PE, Escobar RR, Martins WN, Nunes EO, Vasconcelos FP, et al. Prophylactic intra-aortic balloon pump in high-risk patients undergoing coronary artery bypass surgery: a meta-analysis of randomized controlled trials. Coron Artery Dis. 2012;23:480-6.

6. Barker AB, Townsley MM. Con: prophylactic preoperative use of an intraaortic balloon pump is not indicated in high-risk coronary patients undergoing coronary artery bypass grafting. J Cardiothorac Vasc Anesth. 2015:29:534-5.

7. Holman WL, Li Q, Kiefe Cl, McGiffin DC, Peterson ED, Allman RM, et al. Prophylactic value of preincision intra-aortic balloon pump: analysis of a statewide experience. J Thorac Cardiovasc Surg. 2000;120:1112-9.

8. Dietl CA, Berkheimer MD, Woods EL, Gilbert CL, Pharr WF, Benoit CH. Efficacy and cost-effectiveness of preoperative IABP in patients with ejection fraction of 0.25 or less. Ann Thorac Surg. 1996;62:401-8 discussion 408-9.

9. Kaul TK, Agnihotri AK, Fields BL, Riggins LS, Wyatt DA, Jones CR. Coronary artery bypass grafting in patients with an ejection fraction of twenty percent or less. J Thorac Cardiovasc Surg. 1996;111:1001-12.

10. Khabbaz ZM. Off-pump coronary artery bypass grafting in patients with left main disease: is it really safe? Eur J Cardiothorac Surg. 2011;39:140 author reply $140-1$

11. Vassiliades TA, Nielsen JL, Lonquist JL. Hemodynamic collapse during offpump coronary artery bypass grafting. Ann Thorac Surg. 2002;73:1874-9.

12. Christenson JT, Licker M, Kalangos A. The role of intra-aortic counterpulsation in high-risk OPCAB surgery: a prospective randomized study. J Card Surg. 2003;18:286-94.

13. Yang F, Wang J, Hou D, Xing J, Liu F, Xing ZC, et al. Preoperative intra-aortic balloon pump improves the clinical outcomes of off-pump coronary artery bypass grafting in left ventricular dysfunction patients. Sci Rep. 2016;6: 27645.

14. Vohra HA, Dimitri WR. Elective intraaortic balloon counterpulsation in highrisk off-pump coronary artery bypass grafting. J Card Surg. 2006;21:1-5. 
15. Suzuki T, Okabe M, Handa M, Yasuda F, Miyake Y. Usefulness of preoperative intraaortic balloon pump therapy during off-pump coronary artery bypass grafting in high-risk patients. Ann Thorac Surg. 2004;77:2056-9.

16. Wang J, Yu W, Gao M, Gu C, Yu Y. Preoperative prophylactic Intraaortic balloon pump reduces the incidence of postoperative acute kidney injury and short-term death of high-risk patients undergoing coronary artery bypass grafting: a meta-analysis of 17 studies. Ann Thorac Surg. 2016;101: 2007-19.

17. Miceli A, Fiorani B, Danesi TH, Melina G, Sinatra R. Prophylactic intra-aortic balloon pump in high-risk patients undergoing coronary artery bypass grafting: a propensity score analysis. Interact Cardiovasc Thorac Surg. 2009;9: 291-4.

18. Emmert MY, Salzberg SP, Seifert B, Schurr UP, Hoerstrup SP, Reuthebuch O, et al. Routine off-pump coronary artery bypass grafting is safe and feasible in high-risk patients with left main disease. Ann Thorac Surg. 2010;89:112530

19. Cohen M, Urban P, Christenson JT, Joseph DL, Freedman RJ Jr, Miller MF, et al. Intra-aortic balloon counterpulsation in US and non-US centres: results of the benchmark registry. Eur Heart J. 2003;24:1763-70.

\section{Publisher's Note}

Springer Nature remains neutral with regard to jurisdictional claims in published maps and institutional affiliations.

Ready to submit your research? Choose BMC and benefit from:

- fast, convenient online submission

- thorough peer review by experienced researchers in your field

- rapid publication on acceptance

- support for research data, including large and complex data types

- gold Open Access which fosters wider collaboration and increased citations

- maximum visibility for your research: over $100 \mathrm{M}$ website views per year

At BMC, research is always in progress.

Learn more biomedcentral.com/submissions 